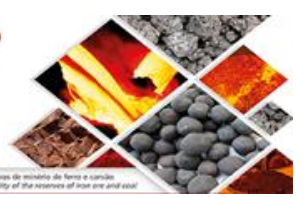

\title{
AUMENTO DA EFICIÊNCIA NA COLETA DE PARTICULADO DO PRECIPITADOR ELETROSTÁTICO DE PROCESSO DO FORNO DE PELOTIZAÇÃO DA SAMARCO MINERAÇÃO*
}

Luiz Cláudio von Sperling Cotta ${ }^{1}$ Maycon Athayde 2 Victor de Menezes Vida/ ${ }^{3}$ Gustavo Ferreira Viana 4 Marcelo de Castro Souza ${ }^{5}$ Sérgio Fernando Nunes ${ }^{2}$

Resumo

Os precipitadores eletrostáticos são equipamentos responsáveis pelo despoeiramento dos gases de processo que atravessam o forno de grelha móvel. O processo de sinterização no forno gera uma grande quantidade de particulado que são retidos por estes equipamentos, portanto têm grande importância no processo da Samarco e para qualidade do ar nas comunidades do entorno. A eficiência dos precipitadores é monitorada através da emissão de particulado no topo das chaminés. Neste estudo foram analisados os fatores elétricos e dimensionais que afetam a eficiência de despoeiramento e, portanto, os mecanismos que recolhem as partículas. Foi também avaliado o balanço de massas do equipamento e a capacidade de coleta de particulado de cada campo do precipitador eletrostático. Desta forma foi realizada a otimização do tempo entre batimentos de placas e ajustes lógicos para a diminuição de entradas de ar falso no precipitador. As ações resultaram em aumento da eficiência do funcionamento do equipamento, com redução do baseline de emissão de particulado. Resultados adicionais foram identificados através da redução de manutenção de válvulas duplas, maior controle operacional.

Palavras-chave: Precipitador eletrostático; Pelotização; Otimização de processo.

\section{DUST COLLECTION EFFICIENCY INCREASE OF PROCESS ELECTROSTATIC} PRECIPITATOR IN SAMARCO PELLETIZING FURNACE

\section{Abstract}

Electrostatic precipitators are facilities responsible for dedusting the process gases that percolate the straight grate furnace. The sintering process generates a large amount of dust which must captured by these facilities, therefore it has had paramount importance in Samarco's process and for the good air quality in the surrounding communities. The dedusting efficiency is monitored through cutting-edge instrumentation technology at the top of the stack. In this study was analyzed the electrical and dimensional factors that affect the efficiency of dedusting and, therefore, the system that collect the particles. It was also evaluated the mass balance of the equipment and the dust collection capacity of each chamber of the electrostatic precipitator. Thus it was performed the optimization of the timespan between hammering of collecting plates and automation improvements to reduce the leakages in the precipitator. The actions resulted in increment of equipment operation efficiency by reduction of dust emission baseline. Additional results identified were reduction of the double valve maintenance and better operational control.

Keyword: ESP; Pelletizing; Process optimization.

\footnotetext{
Engenheiro Metalurgista, Eng., Samarco Mineração, Anchieta, ES, Brasil.

Engenheiro Metalurgista, MSc, Eng., Samarco Mineração, Anchieta, ES, Brasil.

Engenheiro Eletricista, Chefe de Equipe Elétrica, Samarco Mineração, Anchieta, ES, Brasil.

Engenheiro de Automação, Samarco Mineração, Anchieta, ES, Brasil

Técnico de Automação, Samarco Mineração, Anchieta, ES, Brasil.
}

\footnotetext{
* Contribuição técnica ao 44 Seminário de Redução de Minério de Ferro e Matérias-primas, 15ำ Simpósio Brasileiro de Minério de Ferro e 2ํㅗ Simpósio Brasileiro de Aglomeração de Minério de Ferro, 15 a 18 de setembro de 2014, Belo Horizonte, MG, Brasil.
} 


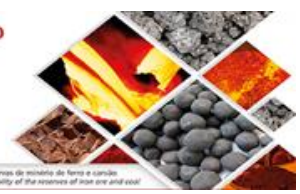

\section{INTRODUÇÃO}

Para se ter um bom ambiente de trabalho e impactar o mínimo possível na região em que atua, a Samarco possui precipitadores eletrostáticos responsáveis por fazer toda a limpeza dos gases que permeiam no processo de pelotização. Estes equipamentos são um dos dispositivos mais comuns para o controle de material particulado na atmosfera. Possuem vantagens quando comparados com outros equipamentos da mesma categoria, pois operam a elevadas temperaturas, atingem alta eficiência de coleta das partículas, possuem baixa perda de carga e baixo custo de manutenção $[1,2,5]$.

A operação do precipitador eletrostático consiste no fornecimento de carga elétrica à partícula, que ocorre através da ionização do gás pelo efeito corona, e então as partículas carregadas são submetidas a um campo elétrico de modo que sua velocidade de migração eletrostática promova a coleta sobre uma placa aterrada, conforme a figura $1[3]$.

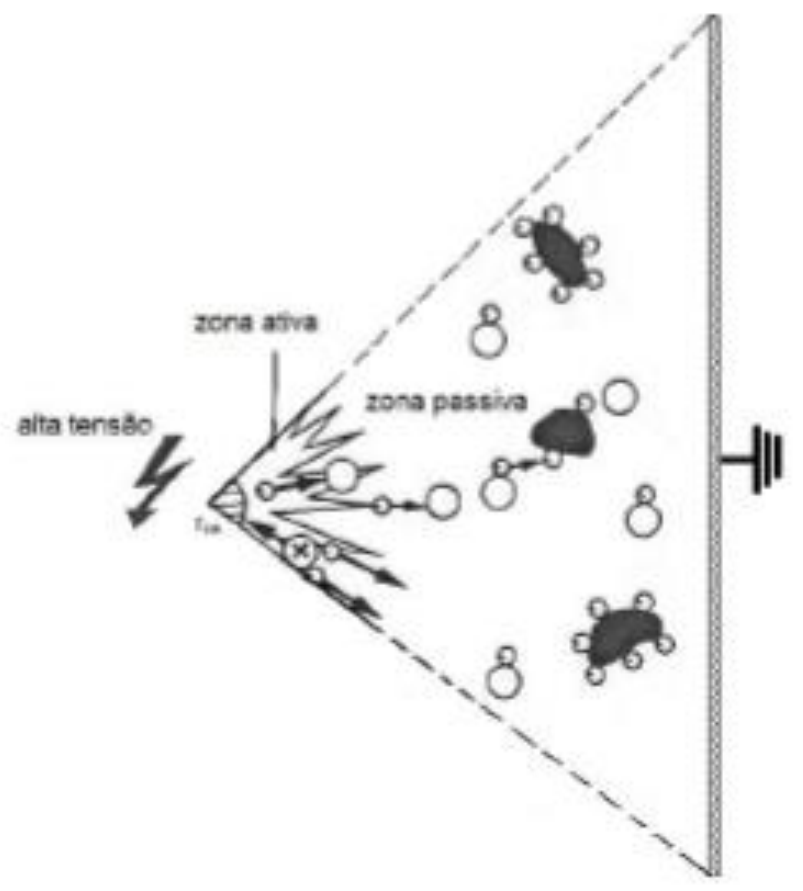

Figura 1 - Princípio do efeito corona [3].

Todos os precipitadores eletrostáticos da Samarco são de simples estágio do tipo placa-fio. Uma fila de fios de descarga é posicionada entre placas de coleta formando um duto e as partículas são depositadas nessas placas devido às forças elétrica e de Van der Waals (figura 2). 


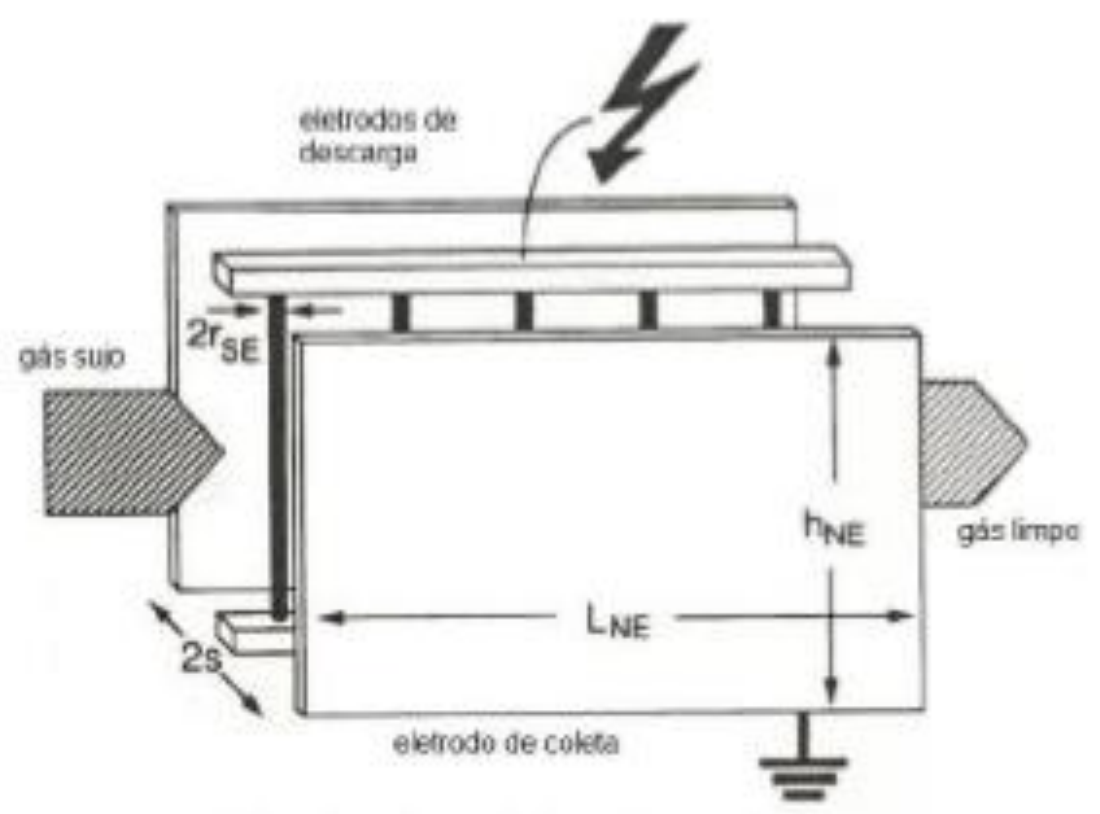

Figura 2 - Modelo de precipitador eletrostático tipo placa-fio [4].

O sistema de descarte é realizado por impacto mecânico e as partículas são depositadas em reservatórios para reutilização no processo de pelotização. É recomendado que a frequência desse impacto mecânico seja a menor possível, uma vez que o batimento das placas promove a ressuspensão de particulado, o que diminui a eficiência do precipitador. Além disso, o batimento de placas impacta diretamente na vida útil do equipamento.

Os reservatórios de coleta de particulado (moegas) também devem atuar de maneira a minimizar a entrada de ar falso no precipitador. Dessa forma, são utilizados mecanismos de válvulas duplas e o modo de operação desse mecanismo também deve ser o mínimo possível. O objetivo do trabalho foi o de aumentar a eficiência de funcionamento mecânico de um precipitador eletrostático de processo e reduzir a emissão de particulado do equipamento.

\section{MATERIAIS E MÉTODOS}

O precipitador avaliado apresenta as seguintes especificações elétricas conforme a figura 3.

* Contribuição técnica ao 44 Seminário de Redução de Minério de Ferro e Matérias-primas, 15ำ Simpósio Brasileiro de Minério de Ferro e $2^{\circ}$ Simpósio Brasileiro de Aglomeração de Minério de Ferro, 15 a 18 de setembro de 2014, Belo Horizonte, MG, Brasil. 


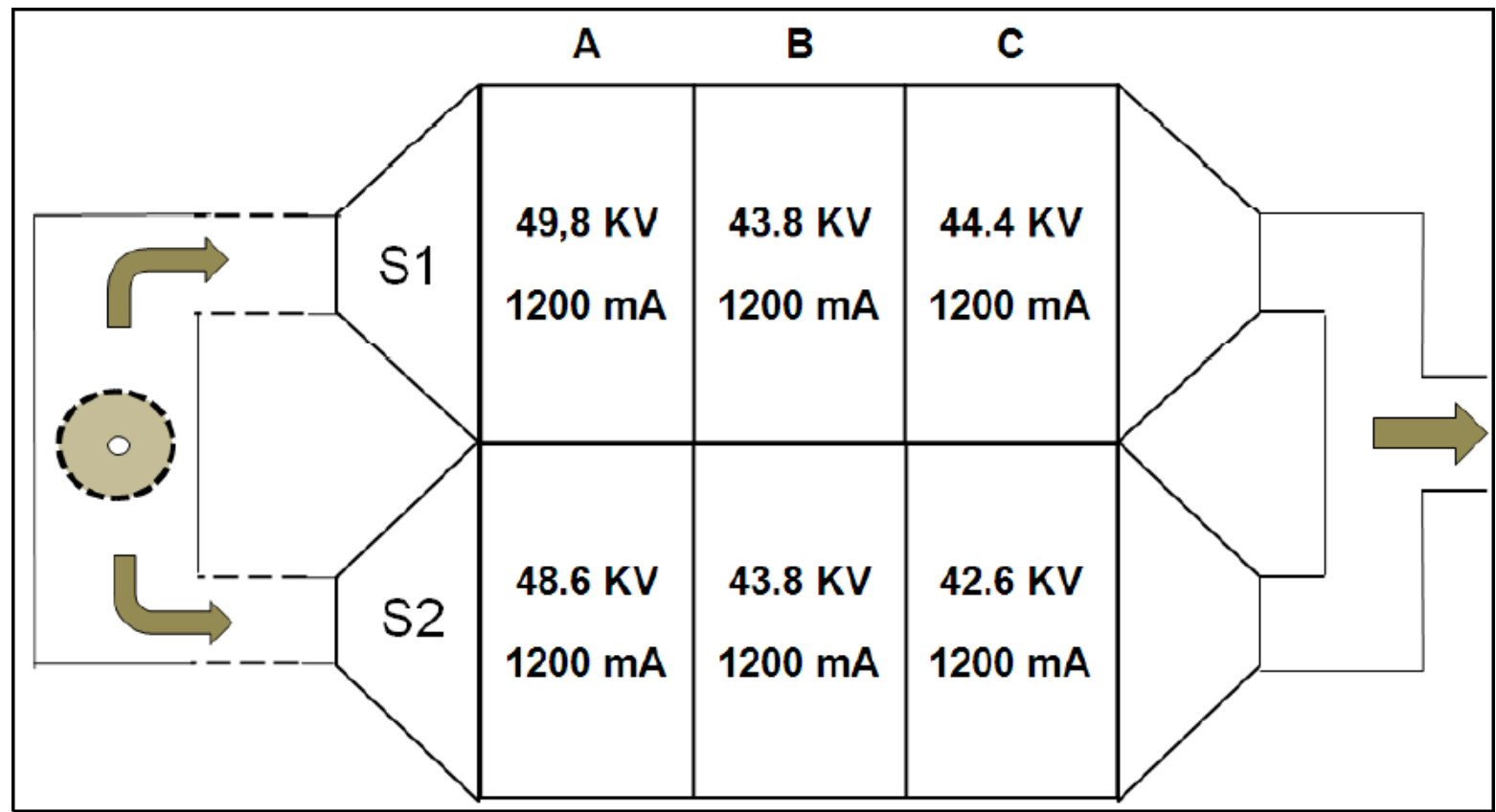

Figura 3 - Dados da corrente e tensão do transformador do precipitador.

\subsection{Avaliação do Balanço de Massa do Precipitador}

Foi coletado material de descarte pelas moegas do precipitador e caracterizado física e quimicamente de acordo com a Tabela 1 e 2.

Tabela 2: Composição Química do particulado retido nas Câmaras S1 (a) e S2 (b).

\begin{tabular}{|c|c|c|c|c|c|}
\hline \multirow{2}{*}{ Substância } & \multicolumn{5}{|c|}{ Câmara S1 } \\
\hline & A1 & A2 & B1 & B2 & $\mathrm{C} 2$ \\
\hline FeT (\%) & 68,07 & 67,89 & 68,20 & 67,78 & 67,02 \\
\hline $\mathrm{Fe}_{2} \mathrm{O}_{3}(\%)$ & 97,34 & 97,08 & 97,53 & 96,93 & 95,84 \\
\hline $\mathrm{FeO}(\%)$ & 0,29 & 0,38 & 0,20 & 0,39 & 0,18 \\
\hline $\mathrm{SiO}_{2}(\%)$ & 1,25 & 1,4 & 1,11 & 1,43 & 1,95 \\
\hline $\mathrm{Al}_{2} \mathrm{O}_{3}(\%)$ & 0,43 & 0,45 & 0,41 & 0,50 & 0,66 \\
\hline $\mathrm{CaO}(\%)$ & 0,59 & 0,68 & 0,56 & 0,72 & 1,04 \\
\hline $\mathrm{MgO}(\%)$ & 0,08 & 0,09 & 0,08 & 0,09 & 0,12 \\
\hline P (\%) & 0,048 & 0,051 & 0,045 & 0,058 & 0,079 \\
\hline P.P.C. & 1,79 & 1,84 & 1,95 & 2,33 & 6,32 \\
\hline P.E. $\left(\mathrm{g} / \mathrm{cm}^{3}\right)$ & 4,953 & 4,936 & 4,946 & 4,882 & 4,470 \\
\hline $\mathrm{TiO}_{2}(\%)$ & 0,040 & 0,041 & 0,042 & 0,044 & 0,043 \\
\hline Mn (\%) & 0,054 & 0,059 & 0,054 & 0,062 & 0,088 \\
\hline C (\%) & 0,351 & 0,400 & 0,300 & 0,416 & 0,424 \\
\hline
\end{tabular}

* Contribuição técnica ao $44^{\circ}$ Seminário de Redução de Minério de Ferro e Matérias-primas, 15ำ Simpósio Brasileiro de Minério de Ferro e 2ํㅗ Simpósio Brasileiro de Aglomeração de Minério de Ferro, 15 a 18 de setembro de 2014, Belo Horizonte, MG, Brasil. 
Redução de Minério de Ferro

\& Tecnologia Mineral

ronmaking and Mineral Technology

itring

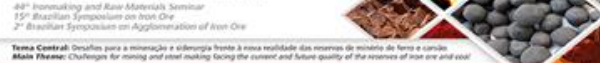

\begin{tabular}{|l|c|c|c|c|c|c|}
\hline \multirow{2}{*}{ Substância } & \multicolumn{7}{|c|}{ Câmara S2 } \\
\cline { 2 - 7 } & $\mathrm{A} 1$ & $\mathrm{~A} 2$ & $\mathrm{~B} 1$ & $\mathrm{~B} 2$ & $\mathrm{C} 1$ & $\mathrm{C} 2$ \\
\hline $\mathrm{FeT}(\%)$ & 67,91 & 68,05 & 68,04 & 67,77 & 67,08 & 66,84 \\
$\mathrm{Fe}_{2} \mathrm{O}_{3}(\%)$ & 97,11 & 97,31 & 97,30 & 96,91 & 95,92 & 95,58 \\
$\mathrm{FeO}(\%)$ & 0,39 & 0,36 & 0,27 & 0,18 & 0,27 & 0,25 \\
$\mathrm{SiO}_{2}(\%)$ & 1,35 & 1,29 & 1,27 & 1,45 & 1,93 & 2,14 \\
$\mathrm{Al}_{2} \mathrm{O}_{3}(\%)$ & 0,45 & 0,42 & 0,45 & 0,51 & 0,64 & 0,71 \\
$\mathrm{CaO}(\%)$ & 0,69 & 0,61 & 0,59 & 0,7 & 1,03 & 1,06 \\
$\mathrm{MgO}(\%)$ & 0,09 & 0,08 & 0,08 & 0,09 & 0,11 & 0,11 \\
$\mathrm{P}(\%)$ & 0,051 & 0,046 & 0,048 & 0,056 & 0,074 & 0,083 \\
$\mathrm{P.P.C.}$ & 1,52 & 1,56 & 1,86 & 2,45 & 6,81 & 5,26 \\
$\mathrm{P.E.}\left(\mathrm{g} / \mathrm{cm}^{3}\right)$ & 4,968 & 4,973 & 4,944 & 4,869 & 4,430 & 4,553 \\
$\mathrm{TiO} \mathrm{F}_{2}(\%)$ & 0,044 & 0,039 & 0,041 & 0,041 & 0,040 & 0,042 \\
$\mathrm{Mn}(\%)$ & 0,060 & 0,054 & 0,057 & 0,063 & 0,086 & 0,087 \\
$\mathrm{C}(\%)$ & 0,456 & 0,363 & 0,310 & 0,351 & 0,421 & 0,454 \\
\hline
\end{tabular}

(b)

Com relação à granulometria, foi avaliado o \%Retido em volume conforme a tabela 2

Tabela 2: Granulometria do particulado retido nas Câmaras S1 (a) e S2 (b).

\begin{tabular}{|c|c|c|c|c|c|c|}
\hline \multicolumn{7}{|c|}{ CÂMARA S1 (\% Retido em Volume) } \\
\hline Granulometria $(\boldsymbol{\mu m})$ & S1A1 & S1 A2 & S1B1 & S1B2 & S1C1 & S1C2 \\
\hline 149 & 87.55 & 96.16 & 99.50 & 98.84 & - & 99.78 \\
\hline 74 & 83.83 & 89.48 & 97.75 & 95.50 & - & 97.92 \\
\hline 44 & 73.67 & 76.02 & 88.02 & 86.84 & - & 95.26 \\
\hline 37 & 68.47 & 69.87 & 81.90 & 82.41 & - & 94.19 \\
\hline 35 & 66.65 & 67.79 & 79.63 & 80.85 & - & 93.83 \\
\hline 30 & 61.27 & 61.83 & 72.67 & 76.25 & - & 92.78 \\
\hline 25 & 54.50 & 54.69 & 63.48 & 70.43 & - & 91.35 \\
\hline 20 & 46.06 & 46.20 & 51.61 & 63.01 & - & 89.16 \\
\hline 15 & 35.67 & 36.27 & 37.02 & 53.36 & - & 85.16 \\
\hline 10 & 23.26 & 24.74 & 21.03 & 40.05 & - & 75.26 \\
\hline 5 & 9.50 & 11.22 & 7.58 & 19.65 & - & 47.37 \\
\hline 1 & 0.58 & 0.82 & 0.27 & 1.14 & - & 3.24 \\
\hline MEDIANA $(\boldsymbol{\mu m})$ & 22.30 & 22.20 & 19.40 & 13.70 & - & 5.50 \\
\hline
\end{tabular}

* Contribuição técnica ao 44 Seminário de Redução de Minério de Ferro e Matérias-primas, 15은 Simpósio Brasileiro de Minério de Ferro e 2ํㅗ Simpósio Brasileiro de Aglomeração de Minério de Ferro, 15 a 18 de setembro de 2014, Belo Horizonte, MG, Brasil. 
Redução de Minério de Ferro

ty

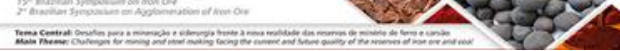

\begin{tabular}{|c|c|c|c|c|c|c|}
\hline \multicolumn{7}{|c|}{ CÂMARA S2 (\% Retido em Volume) } \\
\hline Granulometria $(\boldsymbol{\mu m})$ & S2A1 & S2A2 & S2B1 & S2B2 & S2C1 & S2C2 \\
\hline 149 & 97.40 & 97.86 & 100.00 & 99.95 & 99.60 & 100.00 \\
\hline 74 & 91.71 & 93.92 & 98.91 & 98.76 & 96.92 & 98.91 \\
\hline 44 & 78.54 & 83.20 & 91.14 & 93.50 & 93.63 & 97.08 \\
\hline 37 & 72.10 & 77.46 & 86.49 & 90.50 & 92.12 & 96.34 \\
\hline 35 & 69.86 & 75.41 & 84.79 & 89.42 & 91.58 & 96.10 \\
\hline 30 & 63.38 & 69.28 & 79.56 & 86.16 & 89.93 & 95.39 \\
\hline 25 & 55.40 & 61.39 & 72.61 & 81.88 & 87.66 & 94.51 \\
\hline 20 & 45.69 & 51.31 & 63.37 & 76.11 & 84.35 & 93.30 \\
\hline 15 & 34.14 & 38.64 & 51.08 & 67.84 & 79.03 & 91.13 \\
\hline 10 & 20.93 & 23.44 & 34.70 & 54.17 & 68.91 & 85.30 \\
\hline 5 & 7.46 & 7.80 & 13.60 & 26.86 & 44.00 & 61.60 \\
\hline 1 & 0.48 & 0.41 & 0.77 & 0.97 & 3.39 & 3.93 \\
\hline MEDIANA $(\boldsymbol{\mu m})$ & 22.20 & 19.50 & 14.70 & 9.20 & 6.20 & 4.20 \\
\hline \multicolumn{7}{c}{$(b)$}
\end{tabular}

\subsection{Avaliação dos Mecanismos de Coleta de Particulado}

O precipitador avaliado possui três sistemas de batimentos de placas, um para cada campo, que funcionavam de acordo com a figura 4. O sistema aciona um mecanismo giratório de $180^{\circ}$ que realiza o batimento das placas de uma câmara de cada vez e, portanto, o tempo do batimento das placas é o dobro do apresentado na figura 4.

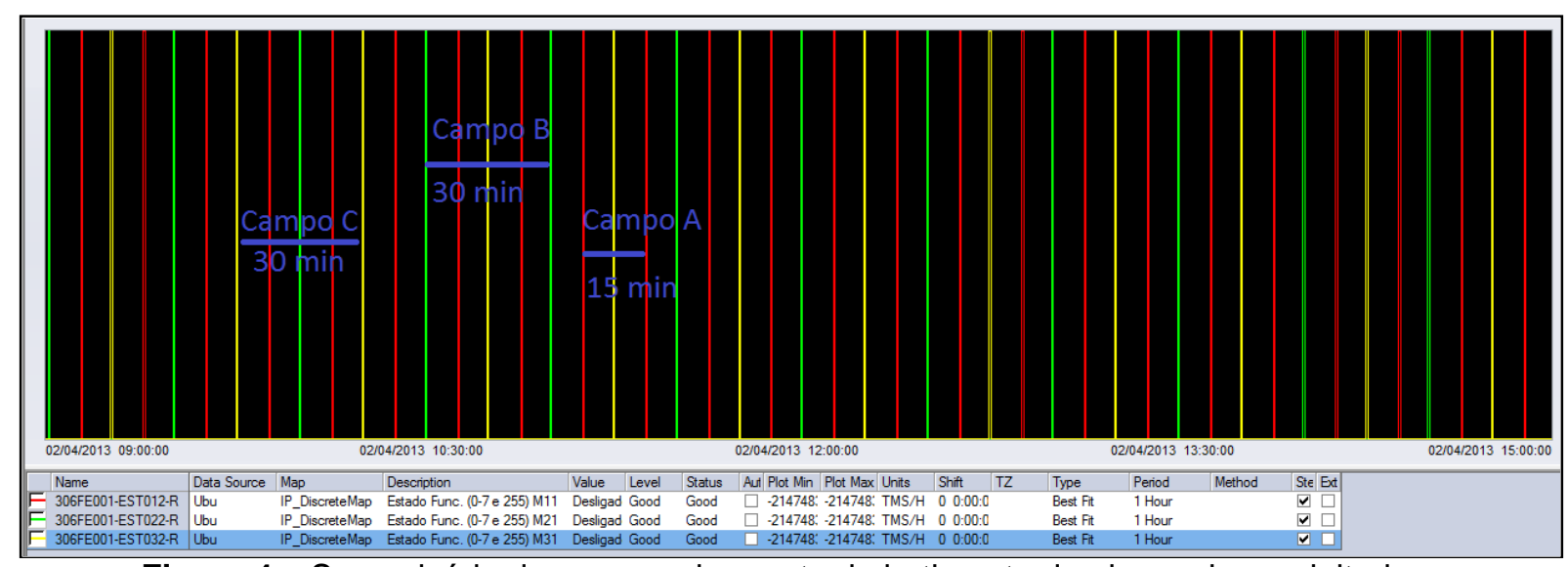

Figura 4 - Supervisório de acompanhamento do batimento de placas do precipitador.

Para cada moega do precipitador tem-se um sistema de válvula dupla (figura 5), sendo doze no total. Esses dispositivos funcionavam ininterruptamente com um acionamento dos pratos a cada seis segundos.

\footnotetext{
* Contribuição técnica ao 44 Seminário de Redução de Minério de Ferro e Matérias-primas, 15ำ Simpósio Brasileiro de Minério de Ferro e 2ํㅗ Simpósio Brasileiro de Aglomeração de Minério de Ferro, 15 a 18 de setembro de 2014, Belo Horizonte, MG, Brasil.
} 

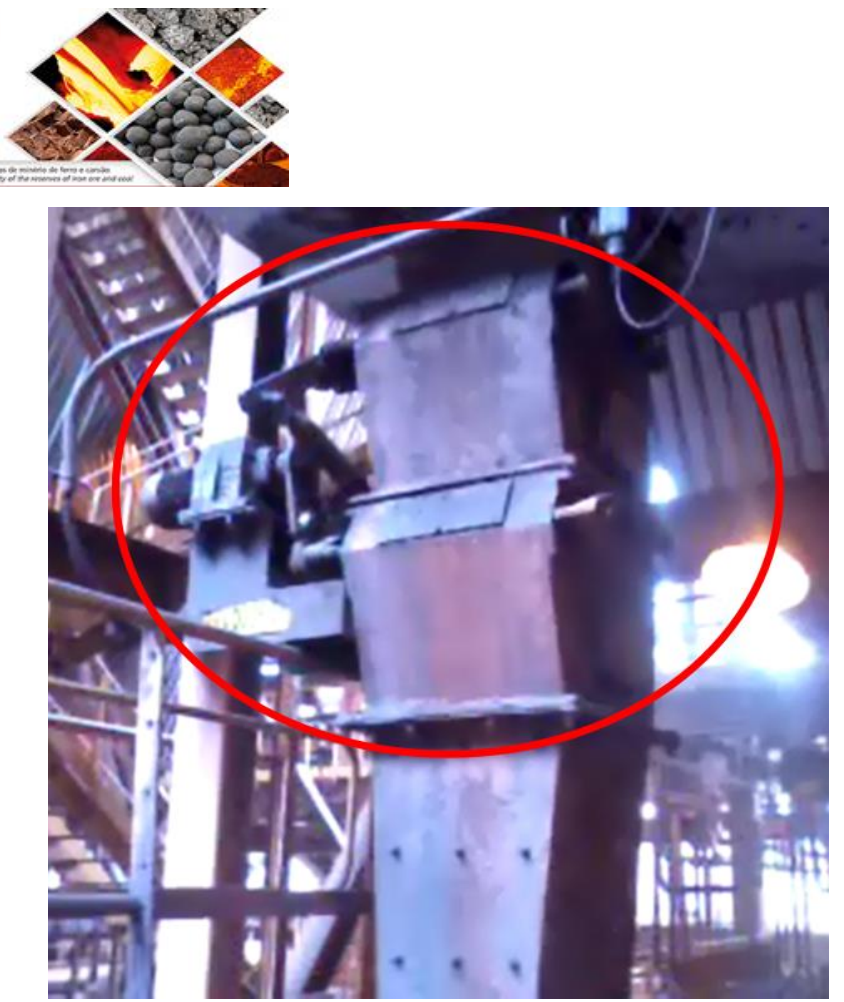

Figura 5 - Mecanismo de válvula dupla das moegas do precipitador.

De acordo com as especificações de projeto e o funcionamento dos mecanismos de coleta de particulado, foi avaliado que cada moega do precipitador era capaz de absorver uma capacidade de $1600 \mathrm{~kg} / \mathrm{h}$. Sendo assim, foi realizada a avaliação das moegas (figura 6) e verificado que o máximo de coleta do precipitador não atinge $70 \mathrm{~kg} / \mathrm{h}$ por moega. A figura 7 apresenta os resultados para as respectivas câmaras e campos.

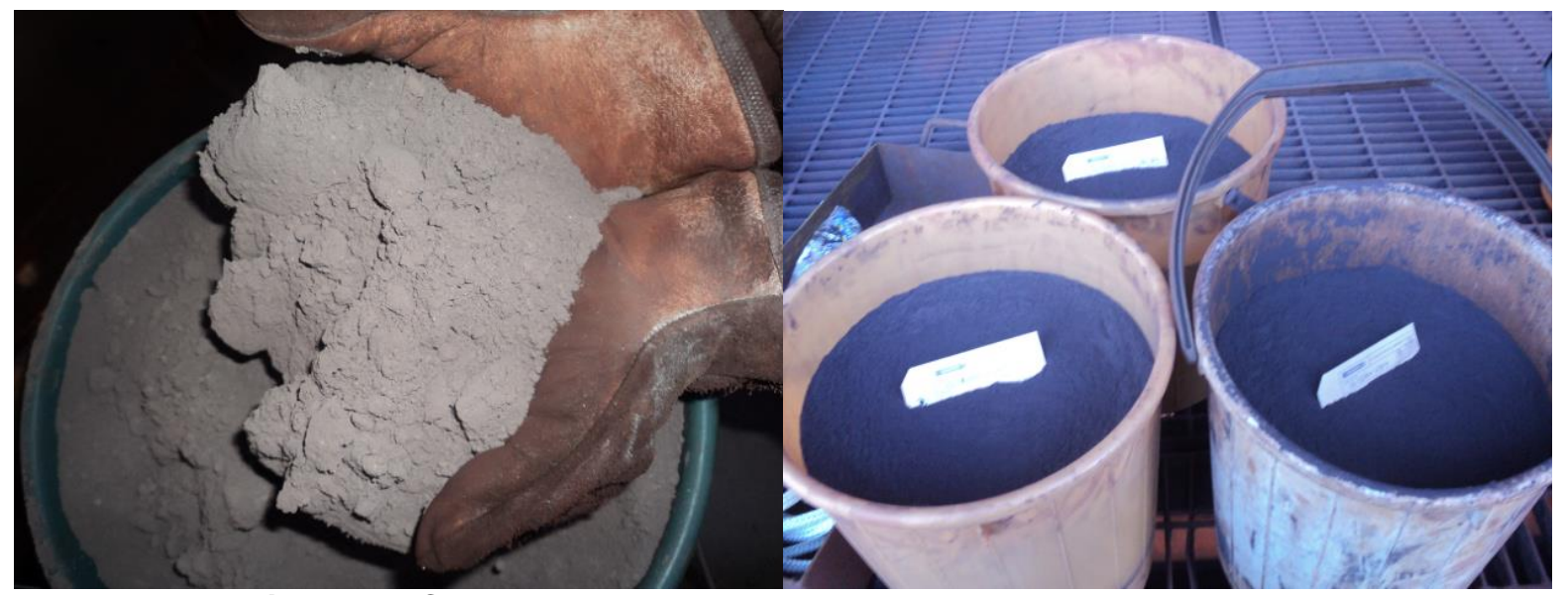

Figura 6 - Coleta de material particulado das moegas do precipitador.

* Contribuição técnica ao 44 Seminário de Redução de Minério de Ferro e Matérias-primas, 15ำ Simpósio Brasileiro de Minério de Ferro e 2ํㅗ Simpósio Brasileiro de Aglomeração de Minério de Ferro, 15 a 18 de setembro de 2014, Belo Horizonte, MG, Brasil. 


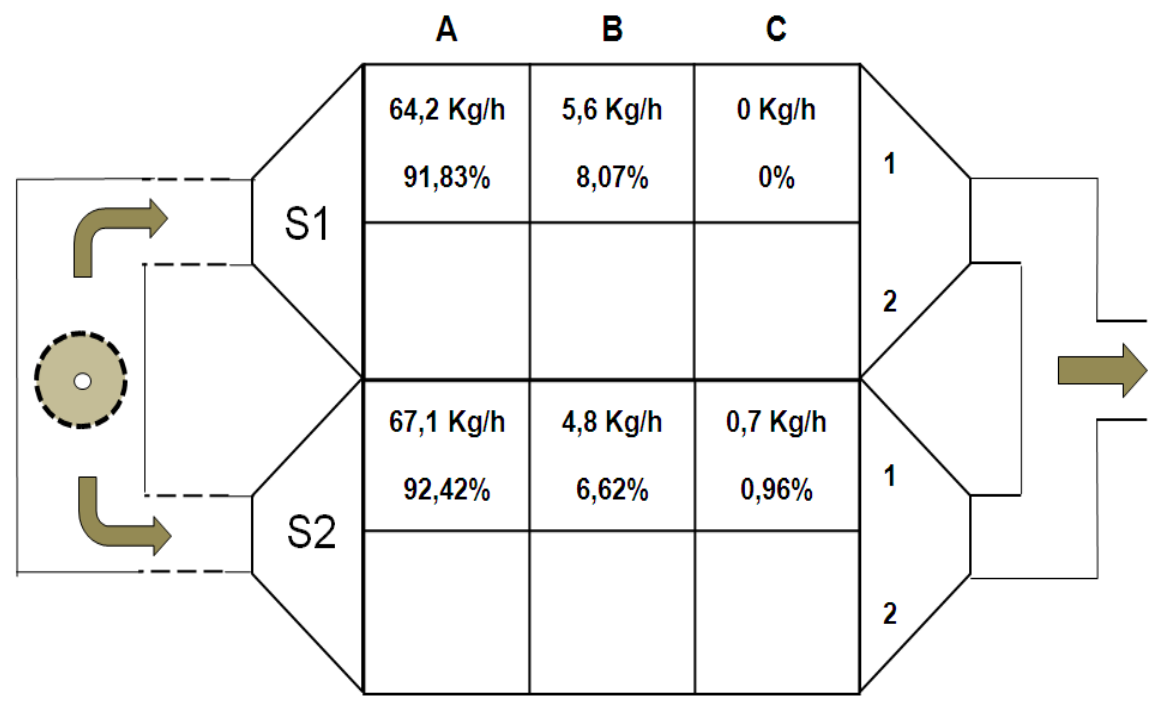

Figura 7 - Taxa de coleta das moegas do precipitador.

\section{RESULTADOS E DISCUSSÕES}

A partir da avaliação do funcionamento do precipitador eletrostático (tabela 3), foram levantadas ações para aumentar a eficiência operacional do equipamento.

Tabela 3: Avaliação geral da eficiência dos equipamentos de coleta de particulado.

\begin{tabular}{|c|c|c|c|c|}
\hline \multirow{2}{*}{ Campo } & \multirow{2}{*}{$\begin{array}{c}\text { Intervalo de } \\
\text { acionamento }\end{array}$} & $\begin{array}{c}\text { Intervalo do ciclo } \\
\text { das válvulas } \\
\text { das Placas (min) }\end{array}$ & \multicolumn{2}{|c|}{$\begin{array}{c}\text { Taxa média de } \\
\text { coleta por moega }\end{array}$} \\
\cline { 4 - 5 } & duplas (s) & $\mathrm{Kg} / \mathrm{h}$ & $\%$ \\
\hline $\mathrm{A}$ & 15 & 6 & 65,65 & $92,2 \%$ \\
\hline $\mathrm{B}$ & 30 & 6 & 5,2 & $7,3 \%$ \\
\hline C & 30 & 6 & 0,35 & $0,5 \%$ \\
\hline
\end{tabular}

Para que houvesse aumento da eficiência do precipitador, foi detectado que as principais ações seriam:

- Aumentar intervalo de tempo entre batimentos nos três campos do precipitador. O objetivo desta ação é formar uma camada mais grossa retida na placa e o material particulado se compactar mais. Com esse aumento da densidade aparente do material compactado haverá menor ressuspensão de particulado direcionado para a chaminé.

- Criar lógica de funcionamento intermitente das válvulas duplas das moegas do precipitador. O objetivo desta ação é minimizar a entrada de ar falso no precipitador através das moegas. Como a maior parte do particulado é coletada somente com o batimento das placas, os mecanismos de válvulas duplas deveriam funcionar somente um breve período após o batimento.

A figura 8 apresenta 0 que foi proposto para modificar o funcionamento dos mecanismos de coleta de particulado.

\footnotetext{
* Contribuição técnica ao 44 Seminário de Redução de Minério de Ferro e Matérias-primas, 15ำ Simpósio Brasileiro de Minério de Ferro e 2ํㅗ Simpósio Brasileiro de Aglomeração de Minério de Ferro, 15 a 18 de setembro de 2014, Belo Horizonte, MG, Brasil.
} 


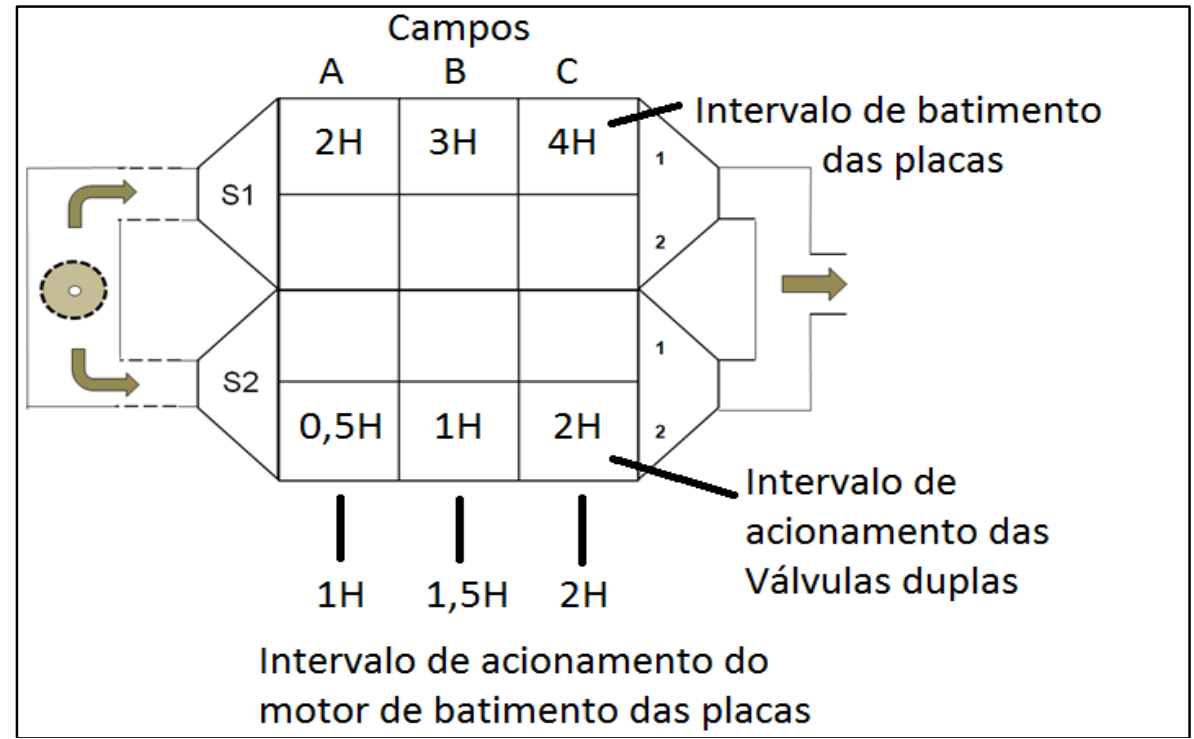

Figura 8 - Proposta de funcionamento dos mecanismos de coleta de particulado.

As modificações de funcionamento dos mecanismos de coleta de particulado foram realizadas durante o mês de abril/2013 e as evidências das modificações foram acompanhadas pelo software de monitoramento da Samarco de acordo com as figuras 9 e 10. Os novos modos de operação reduziram em média $72 \%$ a quantidade de batimentos por dia e a redução no tempo de operação das válvulas duplas foi de $94 \%$ do tempo por dia.

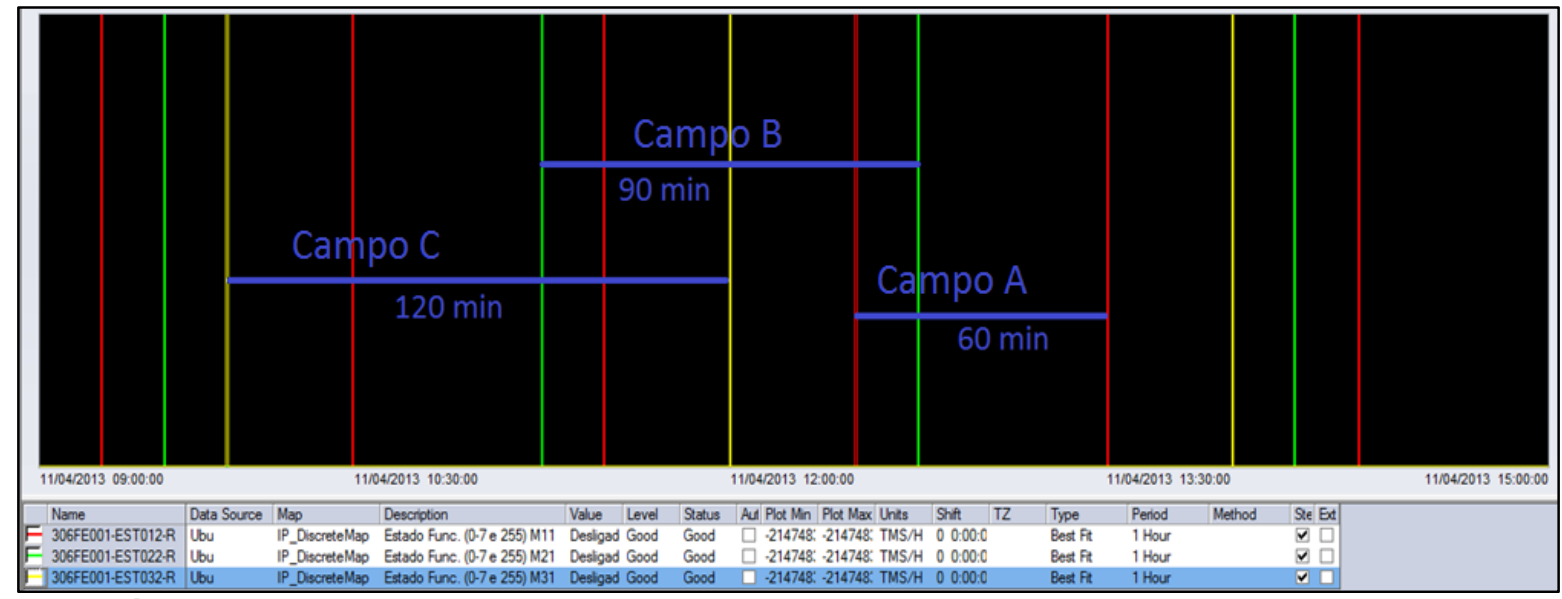

Figura 9 - Novo modo de operação do sistema de batimento de placas do precipitador.

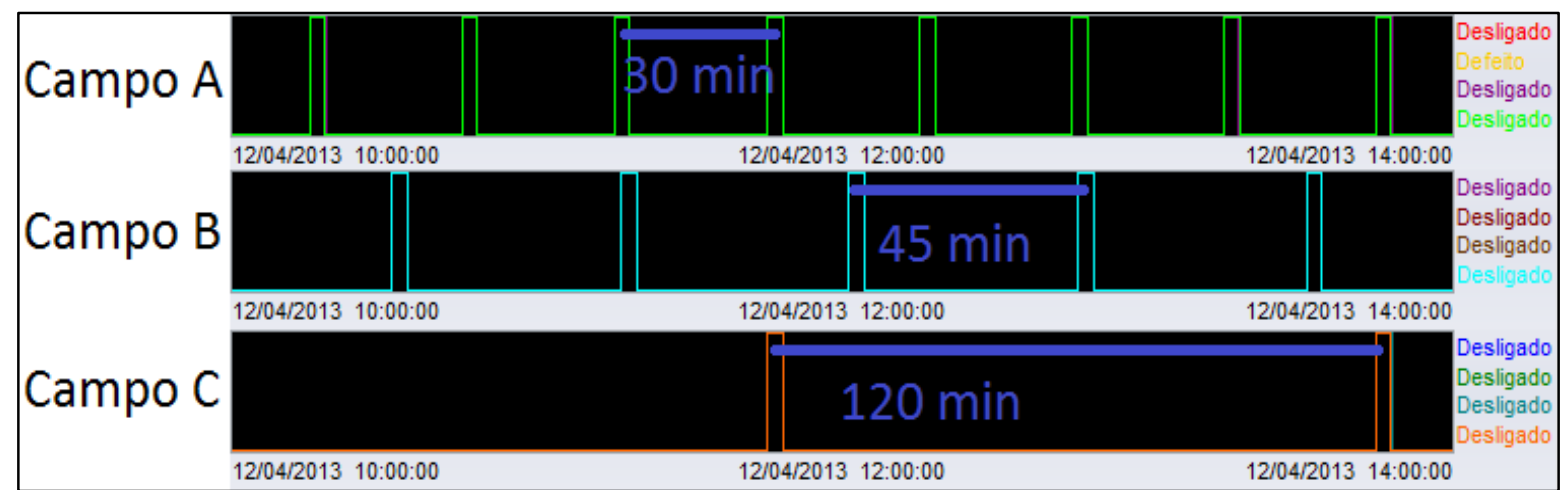

Figura 10 - Novo modo de operação das válvulas duplas do precipitador.

* Contribuição técnica ao 44 Seminário de Redução de Minério de Ferro e Matérias-primas, 15º Simpósio Brasileiro de Minério de Ferro e 2 Simpósio Brasileiro de Aglomeração de Minério de Ferro, 15 a 18 de setembro de 2014, Belo Horizonte, MG, Brasil. 
As evidências de redução da emissão de particulado também são observadas pelo mesmo software de acompanhamento do processo produtivo. A figura 11 apresenta o momento de quando as modificações entraram em operação.

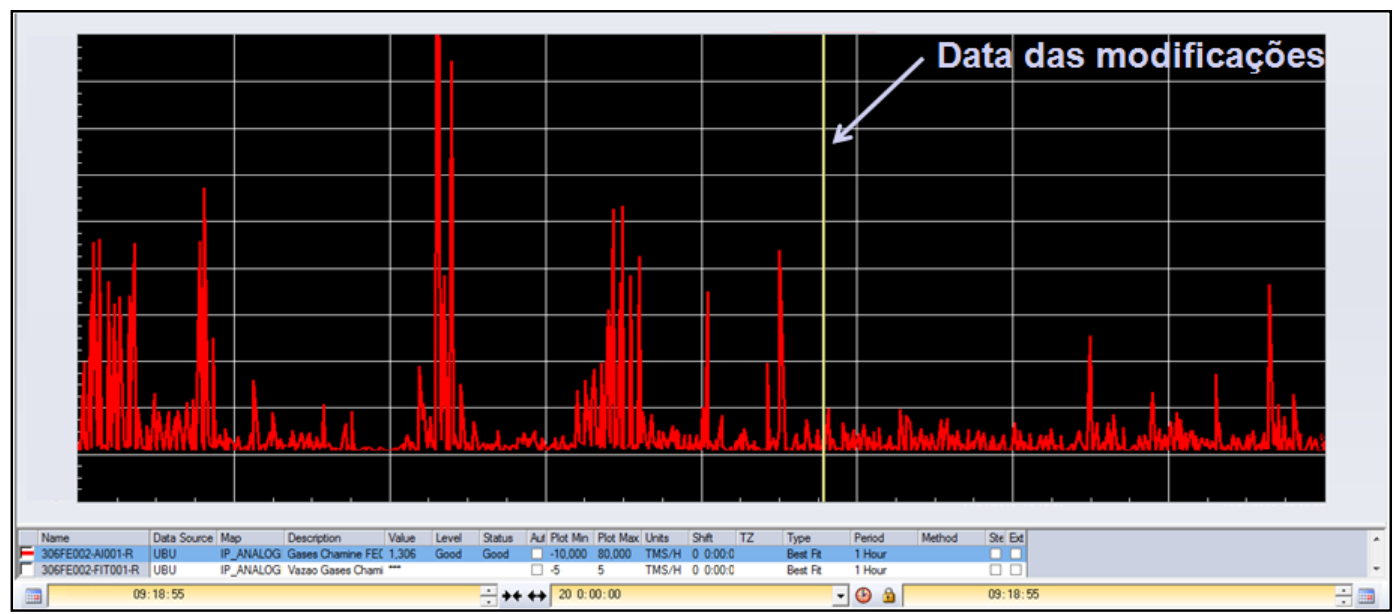

Figura 11 - Monitoramento de emissão de particulado na chaminé do precipitador.

Todavia, para monitorar se de fato houve redução da emissão de particulado, foi monitorada a média diária de particulado durante 159 dias antes e depois e foi possível detectar uma redução significativa de cerca de $70 \%$ da emissão de particulado, conforme a figura 12 .

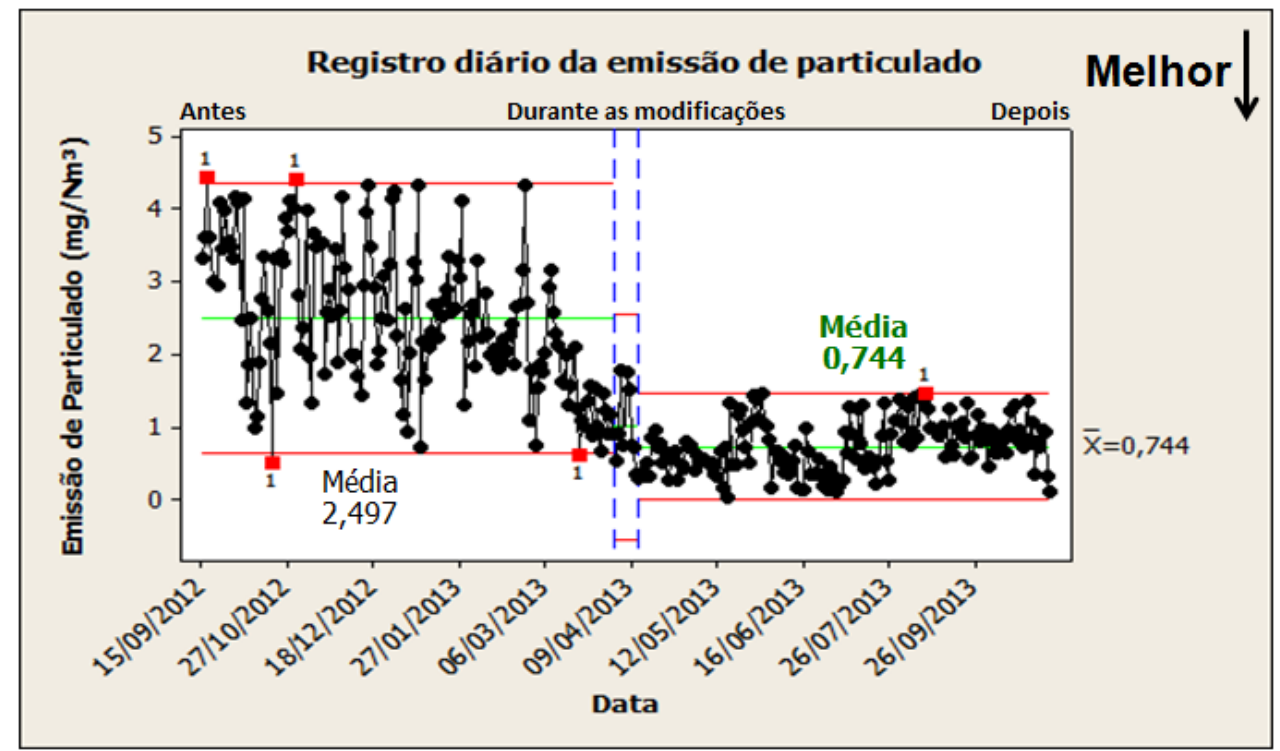

Figura 12 - Emissão média diária de particulado emitido pela chaminé do precipitador.

A fim de se comprovar que essa redução de emissão foi estatisticamente significativa, as amostragens antes e depois foram avaliadas em testes de normalidade e, comprovadas as distribuições normais ( $p$-valores $>0,05$ - figura 13), foram comparadas através do teste comparativo 2-Sample-T (figura 14).

* Contribuição técnica ao 44 Seminário de Redução de Minério de Ferro e Matérias-primas, 15ำ Simpósio Brasileiro de Minério de Ferro e 2ํㅗ Simpósio Brasileiro de Aglomeração de Minério de Ferro, 15 a 18 de setembro de 2014, Belo Horizonte, MG, Brasil. 
Redução de Minério de Ferro
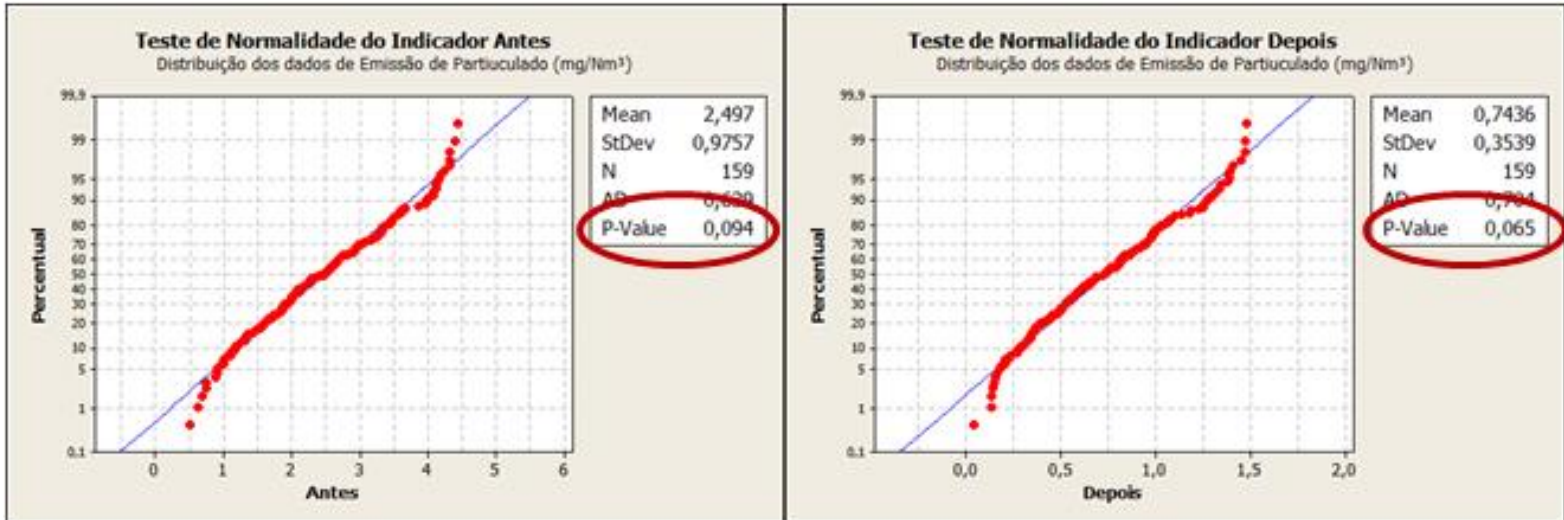

Figura 13 - Teste de normalidade das amostras antes e depois da emissão média diária do precipitador eletrostático.

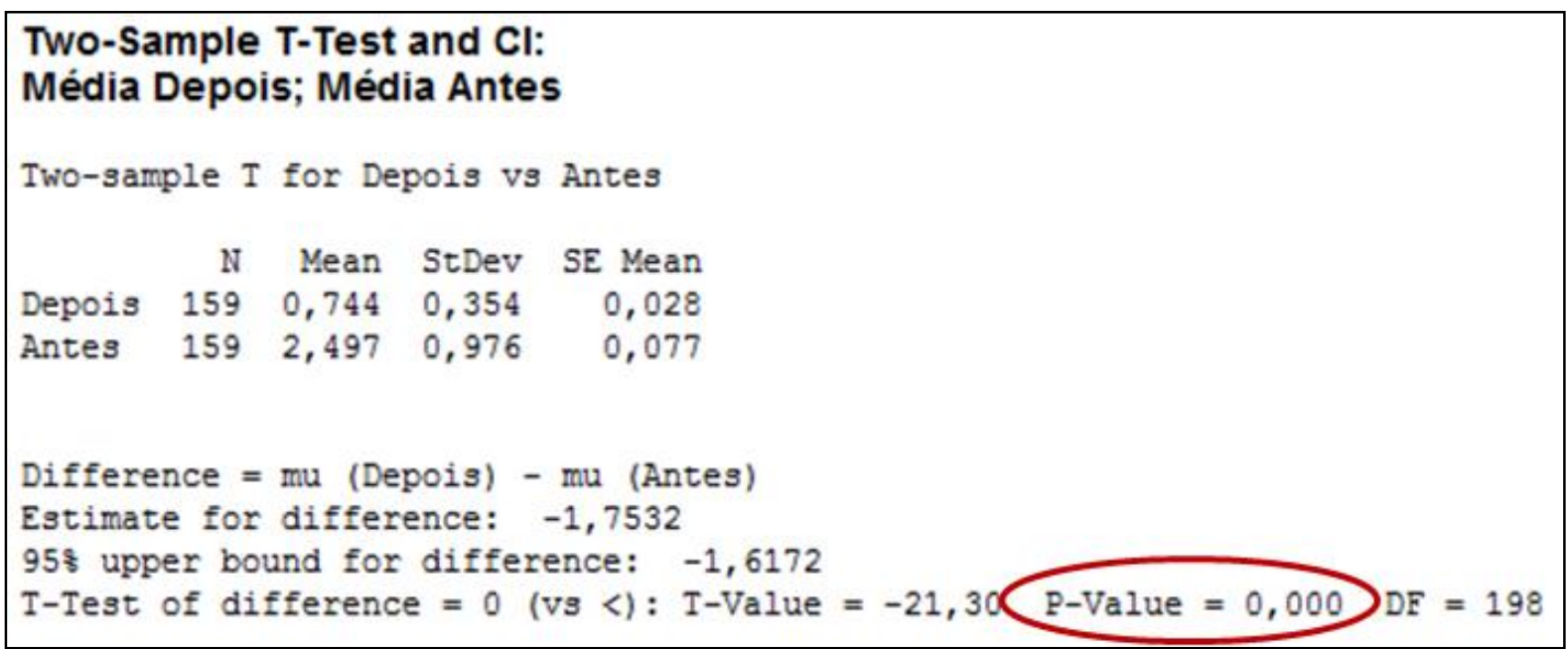

Figura 14 - Teste Comparativo 2-Sample-T entre as amostras antes e depois do precipitador.

O resultado do teste indicou um p-valor $<0,05$ e dessa forma, é possível eliminar a hipótese de que as amostras podem ser iguais. Portanto foi evidenciado física e estatisticamente uma redução da emissão após as ações implementadas nos mecanismos de coleta de particulado do precipitador eletrostático.

\section{CONCLUSÃO}

Através da avaliação de desempenho do precipitador e ações de redução de superprocessamento do equipamento, foi possível não só reduzir o desgaste mecânico dos mecanismos de coleta de particulado, como também houve aumento da eficiência do precipitador evidenciado pela redução da emissão de particulado pela chaminé. Os ganhos desse trabalho atingem áreas de manutenção mecânica, elétrica, operacional e principalmente socioambiental.

\section{Agradecimentos}

Os autores agradecem a todos que indiretamente contribuíram para a realização deste trabalho, em especial à K4 Automação e ao pessoal da Gerência de Produção, Gerência de Engenharia e Gerência de Manutenção da Samarco Mineração em Ponta Ubu.

* Contribuição técnica ao $44^{\circ}$ Seminário de Redução de Minério de Ferro e Matérias-primas, 15ำ Simpósio Brasileiro de Minério de Ferro e 2ํㅗ Simpósio Brasileiro de Aglomeração de Minério de Ferro, 15 a 18 de setembro de 2014, Belo Horizonte, MG, Brasil. 


\section{REFERÊNCIAS}

1 K4 Automação - Relatório Interno do Diagnóstico do Precipitador Eletrostático 06FE001 da Usina 3 da Samarco Mineração, 2012.

$2 \mathrm{Kim} \mathrm{SH}$, Park HS, Lee KW. Theoretical model of electrostatic precipitator performance for collecting polydisperse particles, Journal of Electrostatics, 2001; 50: 177-190.

3 Meira CR. Desempenho de um precipitador eletrostático operando na remoção de nanopartículas de aerossóis, Dissertação de Mestrado, UFSCar, 2009.

4 Parker KR. Applied electrostatic precipitation, Champman \& Hall, 521 p, 1997.

5 Parker KR. Electrical operation of electrostatic precipitators, Institution of Electrical Engineers, 270 p, 2003.

\footnotetext{
* Contribuição técnica ao 44 Seminário de Redução de Minério de Ferro e Matérias-primas, 15ำ Simpósio Brasileiro de Minério de Ferro e $2^{\circ}$ Simpósio Brasileiro de Aglomeração de Minério de Ferro, 15 a 18 de setembro de 2014, Belo Horizonte, MG, Brasil.
} 